\title{
Nouvelles de la Suisse Romande
}

Sandra Feroleto

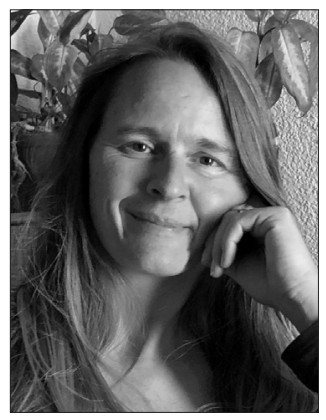

Lautomne est là, avec son lot de petits rhumes et virus et voilà que COVID-19 sévit encore, reprend même sa courbe ascendante en Suisse romande. Plusieurs d'entre vous s'interrogent sur leur pratique, ont pris de nouvelles habitudes via des consultations téléphoniques et/ou par visioconférence. Et plusieurs d'entre vous sont, de ce fait, confrontés aux difficultés de facturation que cela soulève dans le contexte de la délégation, compte tenu de la limitation imposée par l'OFSP. Nous sommes déçus et désolés de ne pas être parvenus à obtenir de meilleures conditions, adaptées à la réalité actuelle des besoins. Cela est d'autant plus navrant que nous sentons l'anxiété générale dans la population, les peurs soulevées, les réactions inhabituelles. La réaction humaine à cette situation sociétale si singulière se polarise, avec d'un côté ceux qui renforcent chaleur et humanisme au service de l'Autre, reviennent à l'essentiel, et de l'autre ceux qui pensent devoir «sauver leurs peaux » quitte à ce que cela soit au prix de liens, qui engagent des actions qu'ils n'auraient probablement jamais mises en œuvre dans une autre période de leur vie.

Bousculés dans nos habitudes, confrontés à nos peurs les plus intimes, nous sommes déstabilisés, remis en cause, secoués par une réalité nouvelle qu'il s'agit d'appréhender. L'impact est particulièrement fort sur notre jeunesse et on constate une hausse drastique des consultations de psychothérapie sollicitées par les étudiants sur les campus académiques romands.

Bien entendu, tout le monde est impacté de façon différente : les métiers de service ont dû repenser leurs pratiques et/ou réorienter leurs priorités. Les professions du numérique sont en pleine explosion et plusieurs start-ups romandes actives dans l'informatique ont vu leurs chiffres d'affaire doubler en quelques mois. Le tourisme s'est profondément modifié. Les voyages nont plus la cote. Leur impact écologique est trop fort et le danger sanitaire qui est brandi à leur annonce font renoncer de nombreuses personnes. Étonnamment, nos buvettes de montagne nont jamais aussi bien travaillé, nombreux étant celles et ceux qui ont préféré fuir les villes et se réfugier dans la sérénité de la montagne, bien heureusement encore épargnée du diktat des masques.

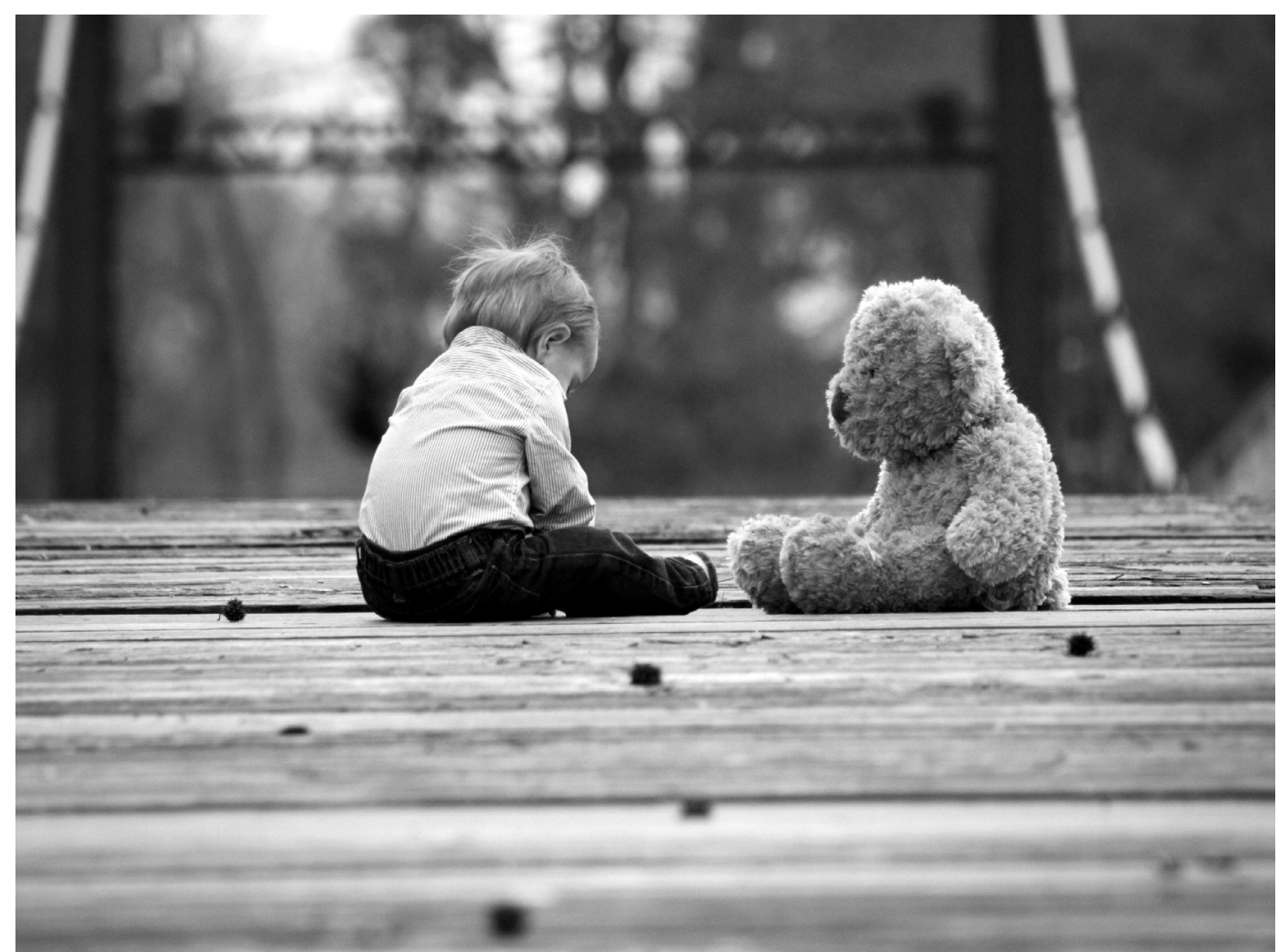


Mais comment toutes ces petites et grandes mutations vont-elles influencer psychologiquement les personnes? Les garderies romandes s'inquiètent pour nos petits bouts qui ne voient plus un sourire et n'ont accès qu'à une expression faciale limitée et pervertie par le masque depuis plusieurs mois.

Certains collègues entendent leurs petits patients leur dire qu'ils sont dangereux pour leurs grands-parents, qu'ils ne peuvent dès lors plus approcher. Comment ces enfants vont-ils pouvoir développer leur estime personnelle et grandir en s'appuyant sur une dynamique intergénérationnelle porteuse de chaleur, de transmission et de perspective dans un tel contexte? Nous traversons donc tous ce bouleversement des représentations, des rôles, des avantages et désavantages. Prenons l'exemple du télétravail : là où une entreprise pouvait envisager précédemment le télétravail comme un avantage offert à son collaborateur, force lui est de constater aujourd'hui que c'est avant tout un avantage pour elle, un moyen simple d'échapper à l'impact éminemment conséquent de mises en quarantaine répétées.

En notre qualité de psychothérapeutes, nous avons en ce moment un rôle très important à jouer, une place à prendre. Auprès des personnes, pour les rassurer, pour les aider à avan- cer avec plus de sérénité vers demain. Pour les aider à rester ou se remettre en mouvement, pour transformer ce qu'elles pensaient acquis, pour réinventer de nouvelles voies, pour appréhender avec confiance les défis que cette période singulière leur pose. Mais nous avons un rôle à jouer auprès des politiques aussi, pour influencer les décisions qui se prennent dans cette gestion de crise, en faisant connaître l'impact psychologique qu'elles ont, l'influence que telle ou telle mesure pourrait avoir sur le développement de l'enfant, sur l'équilibre des gens.

A l'heure où une hausse des primes de l'assurance maladie est à craindre, malgré un certain recul de la facture de soins, espérons plus que jamais que le Conseil fédéral se détermine vraiment et rapidement à basculer au modèle de prescription qui nous rendra enfin accessibles au citoyen lambda qui souffre et ne saurait s'offrir de l'aide aujourd'hui.

La Romandie est particulièrement impactée par le COVID-19, et donc aussi par les mesures mises en ouvre pour le combattre ... gageons qu'elle soit aussi le berceau d'une saine innovation psychothérapique, au service des générations et du monde de demain ...

Sandra Feroleto est membre du comité de l'ASP et déléguée pour la Suisse romande. 